\title{
Study on the Effect of Carboxyl Terminated Butadiene Acrylonitrile (CTBN) Copolymer Concentration on the Decomposition Kinetics Parameters of Blends of Glycidyl Epoxy and Non-Glycidyl Epoxy Resin
}

\author{
Garima Tripathi, Deepak Srivastava \\ Department of Plastic Technology, Harcourt Butler Technological Institute, Kanpur, India \\ E-mail: tgarima@iitk.ac.in, garima.msp@gmail.com \\ Received June 25, 2011; revised August 1, 2011; accepted August 25, 2011
}

\begin{abstract}
The degradation of the epoxy system was studied for the prepared six blend samples with the incorporation of $0 \mathrm{wt} \%$ - $25 \mathrm{wt} \%$ carboxyl terminated butadiene acrylonitrile (CTBN) copolymer, on a dynamic basis using Thermo gravimetric analysis (TGA) technique under a nitrogen atmosphere. The blends were prepared by physical mixing and were cured with diamine. The degradation of each sample followed second-order degradation kinetics, which was calculated by Coats-Redfern equation using best-fit analysis. This was further confirmed by linear regression analysis. The validity of data was checked by t-test statistical analysis. From this value of reaction order, activation energy $(E)$, and pre-exponential factor $(Z)$ were calculated. It was found that the activation energy increased with the addition of liquid elastomer.
\end{abstract}

Keywords: Diglycidyl Ether of Bis-Phenol-A, Cycloaliphatic Epoxy Resin, Carboxyl Terminated Butadiene Acrylonotrile (CTBN) Copolymer, Thermogravimetric Analysis (TGA), Degradation Kinetics

\section{Introduction}

Research in the field of thermal degradation of epoxy systems is of great interest because this is an outstanding problem in the application these systems in different types of environment and for wider usage of these materials as structural adhesives, coatings and as matrices in fiber reinforced composites [1-4]. To characterize the durability of polymers, it is common practice to follow some important properties with time within the temperature range of interest, until a certain preselected limit is attained [1]. In that way reliable data are only valid for the actual temperature under consideration and cannot be transformed to other service temperatures.

The unsatisfactory situation could be overcome, if the changes would not be followed via a certain property, but by a molecular process. Reactions related to degradation also obey Arrhenius kinetics. Thus, when the kinetics of thermal degradation is known, the data can be transformed over the whole temperature range and the temperature-dependent service lifetime can be calculated from these data. Research in thermal degradation of ep- oxy systems is of great interest because this is an outstanding problem in the application these systems in different types of environment and for wider usage of these materials as structural adhesives, coatings and as matrices in fiber reinforced composites [2-5]. For that reason thermogravimetry (TG) technique is widely used for studying the degradation phenomenon of epoxy resins. Various mathematical and experimental methods were developed [5-7] to obtain kinetic parameters viz. order of reaction $(n)$, activation energy $(E)$, pre exponential factor $(Z)$, master curves of degradation [2], and their average life times[3]. Coats-Redfern [8] equation was one of them to describe the aforesaid parameters.

The degradation behavior of diglycidyl ether of bisphenol-A epoxy and CTBN has been studied extensively [9-17], but the decomposition behavior of blends of DGEBA epoxy, cycloalipahtic epoxy and CTBN has hardly been investigated [18]. Keeping this in view, various blend compositions of DGEBA epoxy, cycloaliphatic epoxy and CTBN has been prepared and evaluated their kinetic parameters. 


\section{Experimental}

\subsection{Materials}

The diglycidyl ether of bisphenol-A (DGEBA)—based epoxy resin (LY 556) (epoxide equivalent weight: 192 eq/g), cycloaliphatic epoxy resin (CY 230) (epoxide equivalent weight: $145 \mathrm{eq} / \mathrm{g}$ ) and cure agent was HT 976, (4,4'-diamino diphenyl sulphone) (DDS) were the commercial product (M/s Ciba Speciality Chemicals Pvt. Ltd., Mumbai, INDIA). The elastomer employed was carboxyl terminated butadiene acrylonitrile (CTBN) copolymer (trade name Hycar $1300 \times 13$ ) and was kindly supplied by $\mathrm{M} / \mathrm{s}$ Emerald Performance Materials, LLC, Hong Kong with molecular weight, $\overline{M n} 3500$ containing acrylonotrile content $27 \%$ and carboxyl content $32 \%$.

\subsection{Sample Preparation}

Six blend samples containing $0-25 \mathrm{phr}$ CTBN were prepared according to the procedure similar to that adopted in our previous publication [19] for DGEBA epoxy and CTBN. The calculated quantity of epoxy resin (as per formulations given in Table 1) was, firstly, stirred at $120^{\circ} \mathrm{C}$ to entrap out all air bubbles from it. To this homogeneous mixture, the calculated quantity of DDS was added and stirred at $130^{\circ} \mathrm{C} \pm 5^{\circ} \mathrm{C}$ for half an hour to get clear solution.

\subsection{Curing of Blend Samples}

The cure process of all blend samples followed four steps: First, the epoxy resin (3:1) was degassed followed by addition of $0-25 \mathrm{phr}$ CTBN in the epoxy resin. To this mixture (36 phr) DDS was added and finally, the whole mixture degassed again. The mixture were poured into preheated open iron mold $(8 " \times 8$ ") and cured into hot air oven at $170^{\circ} \mathrm{C}$ for 1 hour and then post cured for 2 hours at $200^{\circ} \mathrm{C}$. Specimens for the entire test were cut from this block (square sheet) of cured material.

Table 1. Composition of epoxy resin with CTBN: blends containing DDS.

\begin{tabular}{cccccc}
\hline S.No. & $\begin{array}{c}\text { DGEBA:CAE } \\
\text { (3:1) (gram) }\end{array}$ & $\begin{array}{c}\text { CTBN } \\
\text { (gram) }\end{array}$ & $\begin{array}{c}\text { Sample } \\
\text { Code }\end{array}$ & $\begin{array}{c}\text { Cure }^{\mathbf{a}} \\
\text { Temp. } \\
\mathbf{T}\left({ }^{\circ} \mathbf{C}\right)\end{array}$ & $\begin{array}{c}\text { Cure }^{\mathbf{b}} \text { Time } \\
\boldsymbol{t} \text { (sec) }\end{array}$ \\
\hline 1 & 100 & 00 & $E P_{3100}$ & 175.94 & 21.8 \\
2 & 95 & 05 & $E P_{3105}$ & 175.41 & 19.2 \\
3 & 90 & 10 & $E P_{3110}$ & 165.41 & 17.6 \\
4 & 85 & 15 & $E P_{3115}$ & 163.92 & 16.7 \\
5 & 80 & 20 & $E P_{3120}$ & 164.00 & 18.0 \\
6 & 75 & 25 & $E P_{3125}$ & - & - \\
\hline
\end{tabular}

a as observed by Dynamic Runs; ${ }^{b}$ as observed by isothermal runs.

\subsection{Characterization of the Blend Samples}

\subsubsection{Fourier-Transform Infra-Red (FTIR) Spectroscopy}

FTIR spectroscopy has been used to monitor the extent of cure of DGEBA/CAE/CTBN/DDS blend systems and the reaction, which occurred when such modifiers were used. For the infrared (IR) measurement a small portion of the cured epoxy system was ground to a fine powder, mixed with potassium bromide $(\mathrm{KBr})$ powder and pressed into a pellet by hand press. FTIR were recorded by Nicollet Magna 750 .

\subsubsection{Cure Schedule by Differential Scanning Calorimetry (DSC) Analysis}

Cure temperature of the prepared samples was observed by taking very little quantity of sample into shallow aluminium pan of DSC (TA instruments, USA; Model DSC 2920), which was sealed by an aluminium cover. This was placed in sample cell of the instrument. The starting temperature programmed rate and final temperature were taken at the heating rate of $10^{\circ} \mathrm{C} / \mathrm{min}$. Dynamic scans were obtained which were used for assessing the cure temperature of the sample.

\subsubsection{Thermogravimetric Analysis (TGA)}

The kinetic parameters for the thermal decomposition of these blends were evaluated by thermogravimetric analyzer (TGA) recorded on TA Instrument (Model Hi.Res.2950 TGA unit interfaced with TA instruments Inc. Thermal Analyst 2100 (Du Pont) control unit. The TGA cell was purged with nitrogen at $60 \mathrm{ml} / \mathrm{min}$ during degradation runs. The amount of sample taken was approximately $5-10 \mathrm{mg}$ in a platinum sample pan. The heating rate in each run was kept at $10^{\circ} \mathrm{C} / \mathrm{min}$ and the temperature range was ambient to $800^{\circ} \mathrm{C}$.

\subsubsection{Kinetic Methods}

The application of dynamic thermogravimetry (DTG) methods holds great promise as a tool for unraveling the mechanisms of physical and chemical processes that occur during polymer degradation. There are various methods which are used to analyze the non-isothermal kinetics. They are as follows:

Flynn-Wall-Ozawa (FWO) method [20,7]

This method was derived from the integral method. The technique assumes that $A$, function of conversion $f(\alpha)$, and $E$ are independent of $T$, whereas $A$ and $E$ are independent of the degree of conversion $(\alpha)$. Equation (2) may then be integrated to give the following in logarithmic form:

$$
\log g(\alpha)=\log (A / E)-\log \beta+\log p(E / R T)
$$


where $g(\alpha)$ is the integral function of conversion and $p$ is the integral function. With Doyle's approximation [8] for the integral, which allows for $E / R T>20$, Equation (3) now can be simplified as

$$
\log \beta=\log (A E / R)-\log g(\alpha)-2.315-0.4567 E / R T
$$

\section{Coats-Redfern (CR) method [8]}

The CR method is also an integral method, and it involves the thermal degradation mechanism. With an asymptotic approximation for resolution of Equation (2), the following equation can be obtained:

$$
\ln \left(\frac{g(\alpha)}{T^{2}}\right)=\ln \left(\frac{A R}{E \beta}\right)-\frac{E}{R T}
$$

The expressions of $g(\alpha)$ for the different mechanisms and $E$ for the degradation mechanism can be obtained from the slope of a plot of $\ln \left[g(\alpha) / T^{2}\right]$ versus 1000/T.

\section{Tang (TM) method [21]}

Following the Doyle's approximation Tang's method comes forward. It says that, with the logarithms of both the side taken and an approximation formula for the solution of Equation (2) (Doyle's approximation) used, the following equation can be obtained:

$$
\begin{aligned}
\ln \left(\frac{\beta}{T^{1.594661}}\right) & =\ln \left(\frac{A E}{R g(\alpha)}\right)+3.635041 \\
& -1.894661 \ln E-\frac{1.001450 E}{R T}
\end{aligned}
$$

The plots of $\ln \left(\beta / T^{1.894661}\right)$ versus $1 / T$ give a group of straight lines. $E$ can be obtained from the slope $1.001450 E / R$ of the regression line.

Kissinger-Akahira-Sunose (KAS) method [22]

This method is an integral is conversional method similar to the FWO method.

$$
\ln \left(\frac{\beta}{T^{2}}\right)=\ln \left[\frac{A R}{E g(\alpha)}\right]-\frac{E}{R T}
$$

The dependence of $\ln \left(\beta / T^{2}\right)$ on $1 / T$ calculated for the same $\alpha$ value at different $\beta$ 's can be used to calculate $E$.

Above mentioned methods are used frequently to calculate the degradation kinetics. In the present investigation we are expanding the Coats and Redfern [9] method to calculate the different parameters.

The percent weights versus temperature curves from TGA were used for this purpose. The data from the TGA curve were utilized in Coats-Redfern equation as given in Scheme 1. This equation was used to determine the values of order of degradation reaction $(n)$, activation energy $(E)$ and pre-exponential factor $(Z)$.

A graph between $\mathrm{X}$ and $\mathrm{Y}$ was plotted using the best fit technique and the value of $n$ was evaluated. This value of $\mathrm{n}$ was further confirmed by linear regression analysis using computer software and the values of coefficient of determination $\left(R^{2}\right)$ were taken as a measure of validity of data. With this value of $\mathrm{n}$, the activation energy $(E)$ and pre-exponential factor $(Z)$ were determined from the slope and intercept values of the $\mathrm{X}$ and $\mathrm{Y}$ plots/regression equations.

\section{Results and Discussion}

\subsection{Fourier-Transform Infrared (FTIR) Spectroscopic Analysis}

Figure 1 showed the FTIR spectrum of blend sample, $E P_{3100}$. There was no shifting of peak positions related to oxirane functionality of glycidyl type DGEBA epoxy resin (912.7 and $834.5 \mathrm{~cm}^{-1}$ ) and non-glycidyl type cycloaliphatic epoxy resin $\left(757.9 \mathrm{~cm}^{-1}\right)$ while physical blending of both the epoxies in comparison to the peak positions of individual epoxy systems and discussed elsewhere [11-13].

As $10 \mathrm{wt} \%$ CTBN was added the blend sample (viz. sample $\left.E P_{3110}\right)$ (Figure 2), the peak intensity of carboxyl group near $1724 \mathrm{~cm}^{-1}$ increased which might be due to increase in carboxylic content of CTBN in the epoxy matrix. The peak intensities of oxirane group of glycidyl type epoxy resin $\left(912.7 \mathrm{~cm}^{-1}\right)$, non-glycidyl type epoxy resin $\left(757.9 \mathrm{~cm}^{-1}\right)$ were found to be increased. This clearly indicated that the occurrence of chemical reaction between the epoxy groups and CTBN occurred.

The change in the peak intensity showed that there was consumption of free functional groups of elastomer, epoxy and amine during curing reaction. By observing all these changes it might be said, that the main reaction of curing was a polyaddition esterification reaction. The complete disappearance of peaks indicated the formation of carboxylate salt between amine catalyst and carboxyl group which rapidly reacted with epoxy to produce epoxy terminated rubber. The IR spectra (Figure 3) of cured product clearly evidenced the process of curing

\subsection{Effect of CTBN on the Cure Schedule of Prepared Blends}

Figures 4 and $\mathbf{5}$ showed the dynamic DSC trace of the sample $E P_{3100}$ and $E P_{3110}$ conducted from $25^{\circ} \mathrm{C}-325^{\circ} \mathrm{C}$ with a heating rate of $10^{\circ} \mathrm{C} / \mathrm{min}$. The related data for all the prepared blends i.e. cure temperature $(T)$ and cure time $(t)$ are shown in Table $\mathbf{1}$. Table $\mathbf{1}$ clearly indicated that the cure time decreased with the incorporation 


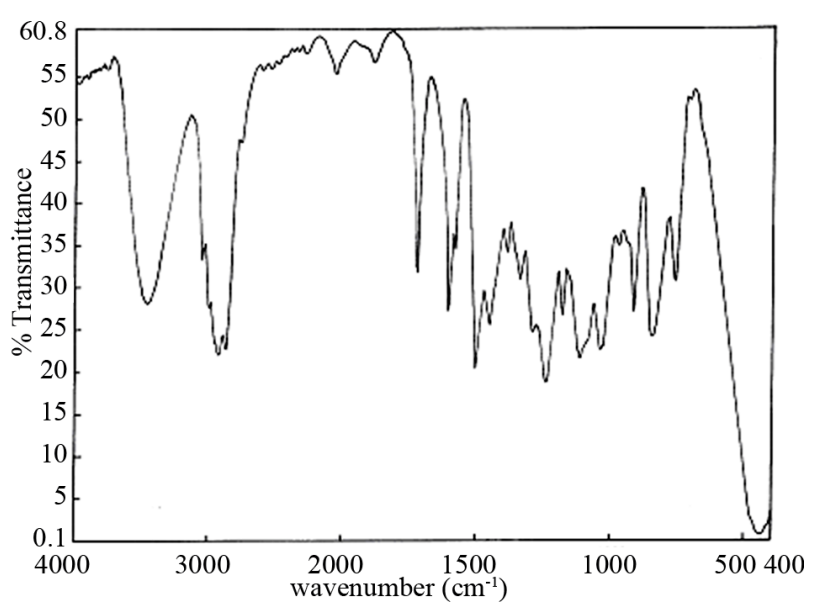

Figure 1. IR spectra of $E P_{3100}$

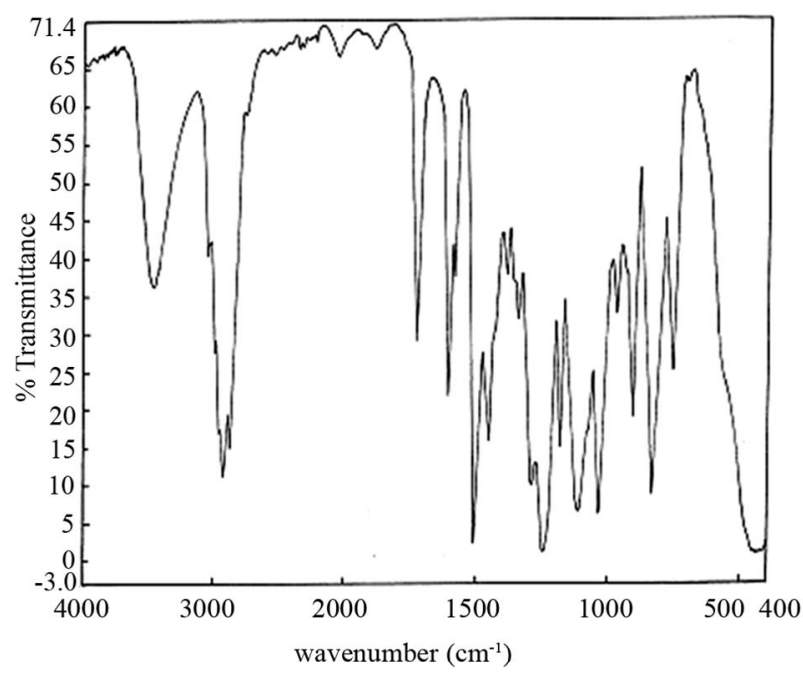

Figure 2. FTIR spectrum of $E P_{3110}$.

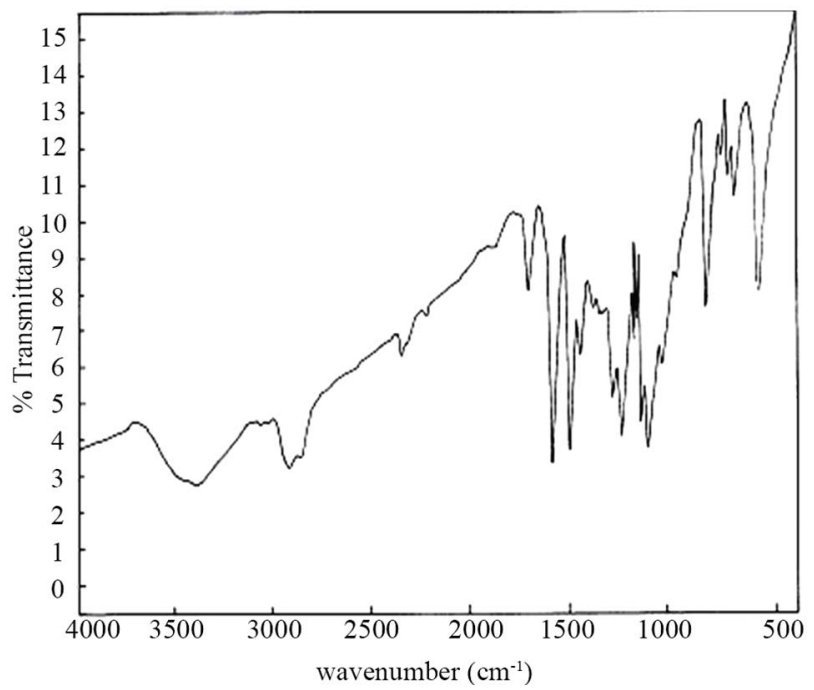

Figure 3. FTIR Spectrum of Cured $E P_{3110}$.

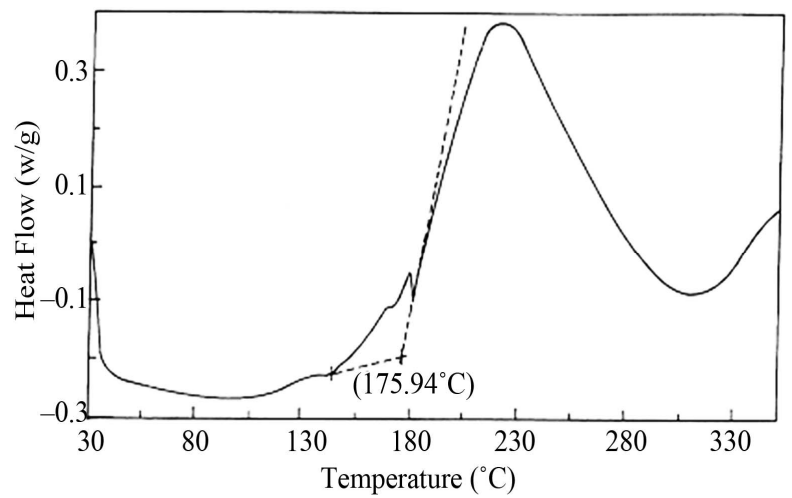

Figure 4. DSC trace of $E P_{3100}$.

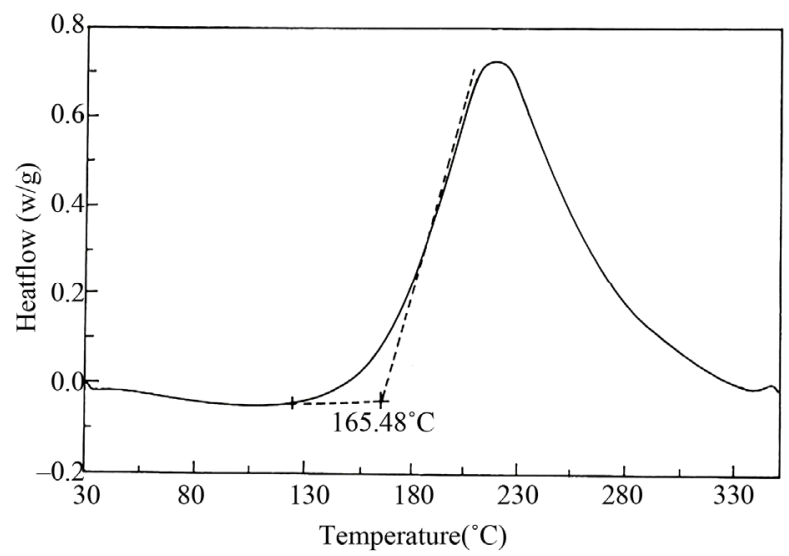

Figure 5. DSC trace of sample $E P_{3110}$

of CTBN in the resin matrix up to $20 \mathrm{wt} \%$ of CTBN. A similar result was drawn by Wise et al. [15] that the use of CTBN rubber modifiers induced a high reactivity of the end groups with the epoxide ring, which would result in shorter curing times. This behavior brought to more perfect network structure. The increasing reaction rate of the epoxy-modified resin may be attributed to the interaction between the carboxyl-terminated groups of CTBN rubber and the epoxide rings of the monomer.

\subsection{Thermogravimetric Analysis}

The onset/initial temperature (IDT) $\left(T_{I}\right)$, maximum rate of mass-loss $(P D T)\left(T_{P}\right)$ and extrapolated final decomposition temperature $(F D T)\left(T_{F}\right)$ were noted from TG traces and are presented in Table 2.

The relative thermal stability of the cured blend resin was compared by determining percent char yield at $800^{\circ} \mathrm{C}$.All the blend systems containing equal weight ratios of DGEBA epoxy and CAE (3:1) having $0 \mathrm{wt} \%$ 25 wt $\%$ CTBN cured with 36 wt $\%$ DDS showed single step degradation (decomposition) behavior (Figure 6). A major loss of $10 \%$ to $75 \%$ was observed in the temperature range of $300^{\circ} \mathrm{C}-550^{\circ} \mathrm{C}$. 
Typical TGA curves of prepared blend samples revealed that the thermal degradation of the system consisted of only one independent step respectively. The experimental data obtained are listed in Table 2. Comparison of initial degradation temperature (IDT) (Figure 7) values showed that, with the incorporation of CTBN, the $\mathrm{T}_{I}$ increased as the weight $\%$ of CTBN increased. This indicated that the addition of CTBN to epoxy system could improve the thermal oxidative stability of the resin system. This conclusion was also reached by the

Table 2. Data obtained from TG traces of prepared blends.

\begin{tabular}{ccccccc}
\hline $\begin{array}{c}\text { S. } \\
\text { No. }\end{array}$ & Cample & $T_{I}$ & $T_{P}$ & $T_{F}$ & \multicolumn{2}{c}{ Mass loss } \\
$\left({ }^{\circ} \mathrm{C}\right)$ & $\left({ }^{\circ} \mathrm{C}\right)$ & $\left({ }^{\circ} \mathrm{C}\right)$ & $(\%)$ & $(\%)$ \\
\hline 1 & $E P 3100$ & $330 \pm 0.5$ & $406.9 \pm 1$ & $610 \pm 1$ & 82.4 & 17.6 \\
2 & $E P 3105$ & $331 \pm 0.85$ & $423.9 \pm 0.5$ & $535 \pm 1.2$ & 75.8 & 24.2 \\
3 & $E P 3110$ & $349 \pm 0.5$ & $426.3 \pm 0.85$ & $545 \pm 1$ & 77.7 & 22.3 \\
4 & $E P 3115$ & $350 \pm 1$ & $423.7 \pm 1$ & $540 \pm 1$ & 76.1 & 23.4 \\
5 & $E P 3120$ & $358 \pm 0.85$ & $420.8 \pm 1$ & $560 \pm 0.95$ & 72.0 & 28.0 \\
6 & $E P 3125$ & $362 \pm 1$ & $425.5 \pm 1$ & $530 \pm 1.5$ & 77.3 & 22.7 \\
\hline
\end{tabular}

$T_{I}$-initial degradation temperature; $T_{P}-$ Peak derivative temperature; $T_{S}$ Stop degradation temperature.

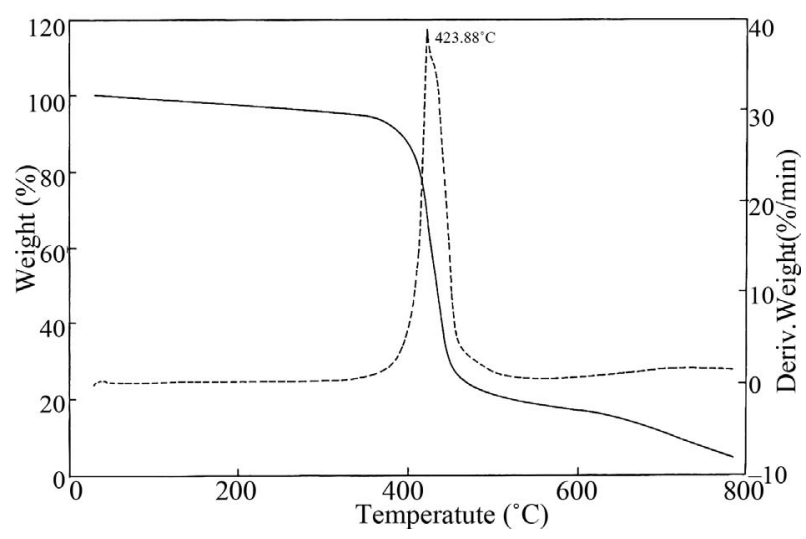

Figure 6. TGA Trace of $E P_{3105}$.

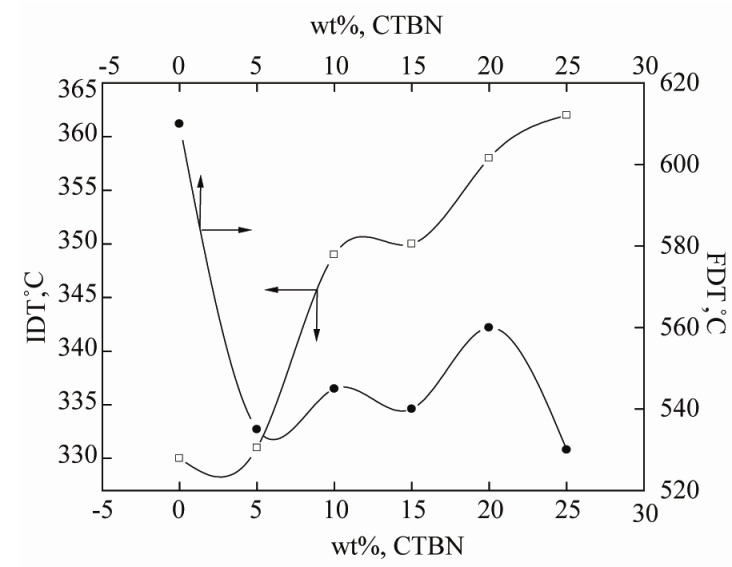

Figure 7. IDT and FDT of prepared blend samples. previous researchers $[9,15-17]$. This conclusion will be further addressed in the following activation energy related discussion.

The char yields of all the prepared samples with CTBN were higher than that of sample $E P_{3100}$ The kinetic parameters, viz. order of reaction $(n)$, activation energy of degradation $(E)$, and pre-exponential factor $(Z)$ of thermal decomposition of the blends of epoxy and CTBN cured with DDS have been evaluated by the dynamic thermo grams of TGA.

The fractional decomposition " $\alpha$ " for the respective temperature has been calculated from TGA data by using the integral equation of Coats-Redfern. If a graph is plotted between $X$ and $Y$ (for $n$ in the range of $0-2$ ) for all sets, the best fit values of $\mathrm{n}$ was found to two (Figure 8). This value of $n$ was further confirmed by linear regression analysis over the TG data in accordance with the values of $X$ and $Y$ obtained from Coats-Redfern equation. The coefficient of correlation, $r$, for this order of reaction was found to be $0.90,0.91,0.95,0.94$ and 0.95 for the prepared blends. Other statistical test [24] data and related regression equations are given in Table 3. It is clear from the results that values of the activation energy increased, but with an associated proportional variation in Z, (Table 4), a phenomenon common in isothermal kinetic treatment [25].

Higher values of activation energies of the blend systems (Figure 9) may be attributed to the presence of polynuclearity in the resin backbone chain. Hence, for a system to be perfectly cured, higher energy was required. This is also clear from the higher char yield of blends. Increasing the activation energy indicated the steric hindrance of the molecules of more complex structure of blends and the cured product with polyamine. The curing reaction itself may be a complex function of the energy of reactive molecules as well as the relative configuration of the reactant molecules reaction process may be hindered because of the presence of polynuclear structure in the backbone. High activation energy for the decomposition of blends led to better thermal stability of such

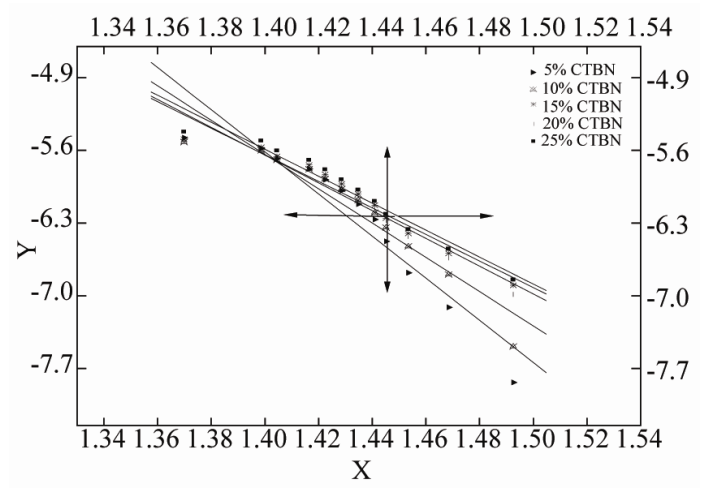

Figure 8. Linear fit data plot for the prepared samples. 


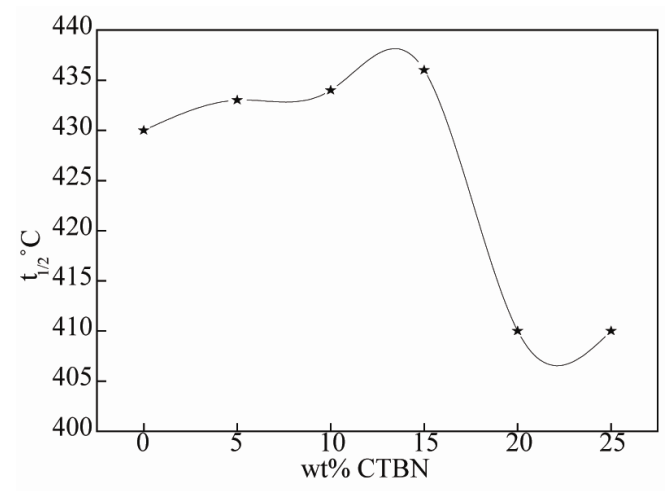

Figure 9. Half-life time ( $\left.t_{1 / 2}\right)$ of prepared samples.
Table 4. Activation energy and preexponential factors of prepared blends.

\begin{tabular}{cccccc}
\hline $\begin{array}{c}\text { S. } \\
\text { No. }\end{array}$ & $\begin{array}{c}\text { Sample } \\
\text { Code }\end{array}$ & $\begin{array}{c}\text { Activation Energy(E) } \\
(\mathbf{K} \cdot \mathbf{C a l} / \mathbf{m o l})\end{array}$ & \multicolumn{2}{c}{$\begin{array}{c}\text { Pre-exponential } \\
\text { Factor(Z) } \\
\left(\mathbf{M i n}^{-1}\right)\end{array}$} \\
\hline & & Calculated & Plot & Calculated & Plot \\
\hline 1 & $E P_{3100}$ & 243.02 & 240.91 & $4.04 * 10^{-6}$ & $3.9 * 10^{-6}$ \\
2 & $E P_{3105}$ & 293.49 & 288.08 & $3.81 * 10^{-6}$ & $3.4 * 10^{-6}$ \\
3 & $E P_{3110}$ & 305.69 & 291.74 & $3.02 * 10^{-6}$ & $2.98 * 10^{-6}$ \\
4 & $E P_{3115}$ & 315.69 & 302.96 & $2.76^{*} 10^{-6}$ & $2.76^{*} 10^{-6}$ \\
5 & $E P_{3120}$ & 387.97 & 354.98 & $2.70^{*} 10^{-6}$ & $2.02^{*} 10^{-6}$ \\
6 & $E P_{3125}$ & 255.64 & 240.18 & $2.98 * 10^{-6}$ & $2.83 * 10^{-6}$ \\
\hline
\end{tabular}

Table 3. Statistical test data of prepared blend samples.

\begin{tabular}{ccccccccc}
\hline No & Sample Code & $\begin{array}{c}\text { Correlation } \\
\text { Coefficient(r) }\end{array}$ & $\begin{array}{c}\text { Standard error of } \\
\text { Coefficient }\end{array}$ & $\begin{array}{c}\boldsymbol{t}_{\text {cal }} \\
\text { (calculated) }\end{array}$ & $\begin{array}{c}\boldsymbol{t}_{\text {tab }} \\
\text { (Table value) }\end{array}$ & $\begin{array}{c}\text { Degree of } \\
\text { freedom }\end{array}$ & $\begin{array}{c}\text { Confidence level } \\
(\boldsymbol{P}=\mathbf{0 . 0 2})\end{array}$ & Regression Equation \\
\hline 1 & $E P_{3100}$ & 0.9503 & 0.0052 & 9.45 & 2.72 & 11 & $98 \%$ & $Y=22.7918-20.2893 X$ \\
2 & $E P_{3105}$ & 0.9451 & 0.0056 & 9.78 & 2.68 & 12 & $98 \%$ & $Y=17.4732-16.5088 X$ \\
3 & $E P_{3110}$ & 0.9521 & 0.0049 & 13.12 & 2.72 & 11 & $98 \%$ & $Y=15.9089-15.3480 X$ \\
4 & $E P_{3115}$ & 0.9053 & 0.0056 & 12.67 & 2.72 & 11 & $98 \%$ & $Y=13.0703-13.3685 X$ \\
5 & $E P_{3120}$ & 0.8992 & 0.0047 & 13.83 & 2.72 & 11 & $98 \%$ & $Y=12.1967-12.7089 X$ \\
6 & $E P_{3125}$ & 0.9414 & 0.0055 & 14.10 & 2.72 & 11 & $98 \%$ & $Y=22.3579-15.9865 X$ \\
\hline
\end{tabular}

blend system. This fact has been previously reported in the literature for different systems. [26-29].

Higher values of pre-exponential factor give rise to a faster high curing reaction [30,31] which might be due to an increased number of collisions which ultimately lead to a higher interaction of reactive sites.

\subsection{Estimation of Half-Life Time, $t_{1 / 2}$ and Life Time, $t_{f}$}

In polymer science, thermal analysis methods have found important applications; among them is the determination of kinetic parameters. Thermo degradation kinetics can be studied by thermogravimetric analysis, which is a useful tool, because the information can be obtained from a single thermogram. Kinetic parameters such as activation energies and pre-exponential factors are calculated using integral and differential methods reported in the literature. With experimental procedures, information about the kinetics of decomposition and in-use lifetime projections can be obtained. The ability to predict the life-time is valuable, because the costs of premature failure in actual end use can be high. TG provides a method for accelerating the life time testing of polymers so that short-term experiments can be used to predict in-use life-time.

An important application of TG kinetic parameters is to predict the highest usable temperature, the optimum processing temperature regions and the estimated lifetime of the polymers. It supplies a simple and convenient approach to use as an accelerated ageing process for quality control experiments. The decomposition kinetics at elevated temperature could be extrapolated back to the service conditions for which the lifetime prediction is required. Two parameters, half-life time $t_{1 / 2}$, and lifetime $t_{f}$ are used to evaluate the service lifetime of the materials. The half-life time is defined as the value of $\alpha$ becomes 0.50 (Figure 10) and the lifetime of polymer to failure is generally defined to be when the degree of decomposition reaches 0.50 .

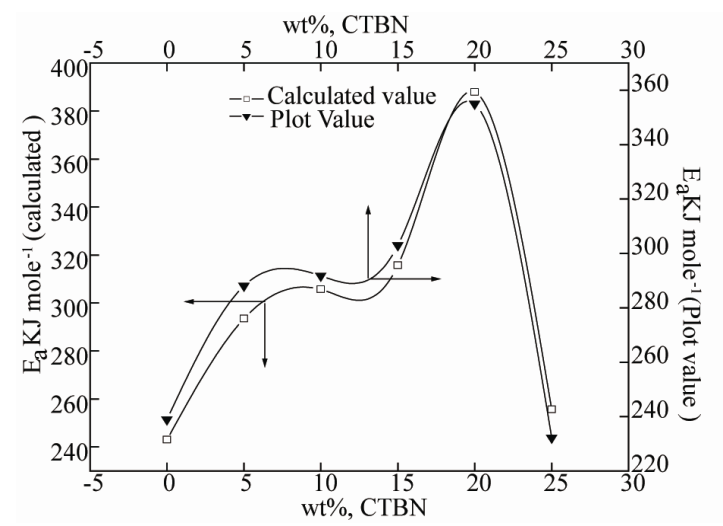

Figure 10. Comparison of $E_{a}$ values of prepared blend samples. 


\section{Conclusions}

On the basis of preceding results and discussion the following conclusions may be drawn:

1) The proposed mechanism for curing reaction of the blend of DGEBA: CAE and carboxyl terminated butadiene Acrylonitrile copolymer (CTBN) in presence of 4, 4'-diamino diphenyl sulphone (DDS) was found to be well suitable for such system, which was confirmed by FTIR analysis.

2) The addition of CTBN liquid rubber improved the thermal stability of the pure epoxy resin.

3) The degradation of ternary blends proceeds with 2ndorder, which was determined by best-fit and regression analysis. The obtained data were found to be highly significant (confirmed by statistical analysis) i.e. the change in the value of $X$ (temperature) will change the value of $Y$ (activation energy) significantly.

4) The blends were found to be more thermally stable having high activation energy as the CTBN content in the blend was increased upto $20 \%$.

5) Half-life, $t_{1 / 2}$ of the prepared samples was increased upto $15 \mathrm{wt} \%$ CTBN addition and decreased thereafter.

\section{References}

[1] E. S. W. Kong, S. M. Lee and H. G. Nelson, "Physical Aging in Graphite/Epoxy Composites," Polymer Composites, Vol. 3, No. 1, 1982, pp. 29-33. doi: $10.1002 / p c .750030106$

[2] F. Fraga and M. R. Núñez, "Activation Energies for the Epoxy System BADGE $n=0 / \mathrm{m}-\mathrm{XDA}$ Obtained Using Data from Thermogravimetric Analysis," Journal of Applied Polymer Science, Vol. 80, No. 5, 2001, pp. 776-782. doi:10.1002/1097-4628(20010502)80:5<776::AID-APP1 154>3.0.CO;2-8

[3] F. Fraga and E. R. Munez, "Master Curves and Lifetime prediction for the Epoxy System Badge $n=0 / \mathrm{m}-\mathrm{XDA}$ by Thermogravimetric Analysis," Journal of Applied Polymer Science, Vol. 82, No. 2, 2001, pp. 461-466. doi:10.1002/app.1872

[4] F. Fraga and E. R. Munez, "Lifetime Predictions for the Epoxy System BADGE $n=0 / m-X D A$ Using Kinetic Analysis of Thermogravimetry Curves," Journal of Applied Polymer Science, Vol. 83, No. 8, 2002, pp. 19621696. doi:10.1002/app.10091

[5] L. Barral, J. Cano, J. Lopez, I. LopezBereno, P. Nogeceria, C. Ramirez and M. J. Abad, "Degradation Kinetics of an Epoxy/Cycloaliphatic Amine Resin under Isothermal and Non-isothermal Conditions," Journal of Thermal Analysis and Calorimetry, Vol. 55, No. 1, 1999, pp. 37-45. doi:10.1023/A:1010115618176

[6] L. A. Wall, "Title of This Paper," J. Res. Nat. Bur. Standards A Phys. Chem., Vol. 70A, No. *, 1996, pp. 487$* * *$.
[7] T. Ozawa, "A New Method of Analyzing Thermogravimetric Data," Bulletin of the Chemical Society of Japan, Vol. 38, No. 11, 1965, pp. 1881-1886. doi:10.1246/bcsj.38.1881

[8] A. W. Coats, "Kinetic Parameters from Thermogravimetric Data," Nature, Vol. 201, 1964, pp. 68-69. doi: $10.1038 / 201068 \mathrm{a} 0$

[9] C. D. Doyle, "Series Approximations to the Equation of Thermogravimetric Data," Nature, Vol. 207, 1965, pp. 290-291. doi:10.1038/207290a0

[10] J. Y. Lee, H. K. Choi, M. J. Shim and S. W. Kim, "Title of This Paper," Journal of Industrial and Engineering Chemistry, Vol. 4, No. 1, 1998, pp. 7-11.

[11] V. Nigam, D. K. Setua and G. N. Mathur, "Characterization of Rubber Epoxy Blends by Thermal Analysis," Journal of Thermal Analysis and Calorimetry, Vol. 64, No. 2, 2001, pp. 521-527. doi:10.1023/A:1011586715864

[12] A. Gu and G. Ling, "Thermal Stability and Kinetics Analysis of Rubber-Modified Epoxy Resin by HighResolution Thermogravimetric Analysis," Journal of Applied Polymer Science, Vol. 89, No. 13, 2003, pp. 3594 3600. doi:10.1002/app.12786

[13] M. L. Auad, P. M. Frontini, J. Borrajo and I. M. Ranguren, "Liquid Rubber Modified Vinyl Ester Resins: Fracture and Mechanical Behavior," Polymer, Vol. 42, No. 8, 2001, pp. 3723-3730. doi:10.1016/S0032-3861(00)00773-4

[14] R. J. Day, P. A. Lovell and A. A. Wazzan, “Toughened Carbon/Epoxy Composites Made by Using Core/Shell Particles," Composites Science and Technology, Vol. 61, No. 1, 2001, pp. 41-56. doi:10.1016/S0266-3538(00)00169-X

[15] C. W. Wise, W. D. Cook and A. A. Goodwin, "CTBN Rubber Phase Precipitation in Model Epoxy Resins," Polymer, Vol. 41, No. 12, 2000, pp. 4625-4633. doi:10.1016/S0032-3861(99)00686-2

[16] I. McEvan, R. A. Pethrick and S. J. Shaw, "Water Absorption in a Rubber-Modified Epoxy Resin; Carboxy Terminated Butadiene Acrylonitrile-Amine Cured Epoxy Resin System," Polymer, Vol. 40, No. 15, 1999, pp. 4213-4222. doi:10.1016/S0032-3861(98)00649-1

[17] E. Pezzati, P. Balidini and A. Schiraldi, "Epoxy Polymers: Effect of the Elastomee in the Kinetics of Polymerization," Thermochemic Acta, Vol. 122, No. 1, 1987, pp. 29-35. doi:10.1016/0040-6031(87)80102-8

[18] G. Tripathi and D. Srivastava, "Studies on the PhysicoMechanical and Thermal Characteristics of Blends of DGEBA Epoxy, 3,4 Epoxy Cyclohexylmethyl, 3',4'-Epoxycylohexane Carboxylate and Carboxyl Terminated Butadiene Co-Acrylonitrile (CTBN)," Materials Science and Engineering: A, Vol. 496, No. 1-2, 2008, pp. 483-493. doi:10.1016/j.msea.2008.06.035

[19] G. Tripathi and D. Srivastava, "Effect of Carboxyl-Terminated Poly(butadiene-co-acrylonitrile) (CTBN) Concentration on Thermal and Mechanical Properties of Binary Blends of Diglycidyl Ether of Bisphenol-A (DGEBA) Epoxy Resin,” Materials Science and Engineering: 
A, Vol. 443, No. 1-2, 2007, pp. 262-269. doi:10.1016/j.msea.2006.09.031

[20] J. H. Flynn and L. A. Wall, "A Quick, Direct Method for the Determination of Activation Energy from Thermogravimetric Data," Journal of Polymer Science Part B: Polymer Letters, Vol. 4, No. 5, 1966, pp. 323-328. doi:10.1002/pol.1966.110040504

[21] W. Tang, Y. Liu, C. H. Zhang and C. Wang, "Title of This Paper," Thermochimica Acta, Vol. 40, No. *, 2003, pp. 839-***.

[22] H. F. Kissinger, "Reaction Kinetics in Differential Thermal Analysis," Analytical Chemistry, Vol. 29, No. 11, 1957, pp. 1702-1706. doi:10.1021/ac60131a045

[23] L. Calabrese and A. Valenza, "The Effect of a Liquid CTBN Rubber Modifier on the Thermo-Kinetic Parameters of an Epoxy Resin during a Pultrusion Process," Composites Science and Technology, Vol. 63, 2003, pp. 851-860.

[24] C. Gupta and V. K. Kapoor, "Title of This Paper," Fundamental of Mathematical Statistics (S. Chand and Sons. India) 1984.

[25] C. P. Raghunandan, R. L. Bindu and K. N. Niran, "A Study of the Oxidative Degradation of Phenol-Formaldehyde Polycondensates Using Infrared Spectroscopy," Journal of Applied Polymer Science, Vol. 103, No. 1,
1963, pp. 103-107. doi:10.1002/app.1963.070070110

[26] M. G. Kim, W. L. S. Nich and R. M. Meacham, "Study on the Curing of Phenol-Formaldehyde Resol Resins by Dynamic Mechanical Analysis," Industrial \& Engineering Chemistry Research, Vol. 30, No. 4, 1991, pp. 798803. doi:10.1021/ie00052a027

[27] T. Monetta and F. Belluchi, "Protective Properties of Epoxy-Based Organic Coatings on Mild Steel," Progress in Organic Coatings, Vol. 21, No. 4, 1993, pp. 353-369. doi:10.1016/0033-0655(93)80050-K

[28] K. Srivastava, M. K. Kaushik, D. Srivastava and S. K. Tripathi, "The Effect of Orientation of Various Phenols on the Degradation Kinetics of Blends of Resole and Epoxy," Journal of Applied Polymer Science, Vol. 102, No. 5, 2006, pp. 4171-4176. doi:10.1002/app.24493

[29] R. S. Baur, "Epoxy Resin Chemistry II," ACS Symposium Series, No. 221, Washington, DC, 1979.

[30] A. F. Yee and R. A. Pearson, "Toughening Mechanisms in Elastomer-Modified Epoxies Part 1 Mechanical Studies," Journal of Materials Science, Vol. 21, No. 7, 1986, pp. 2462-2467. doi:10.1007/BF01114293

[31] J. Criado, J. Malek and A. Ortega, "Applicability of the Master Plots in Kinetic Analysis of Non-Isothermal Data," Thermochimica Acta, Vol. 147, No. 2, 1998, pp. 377-385. doi:10.1016/0040-6031(89)85192-5 